University of Nebraska - Lincoln

DigitalCommons@University of Nebraska - Lincoln

$7-22-2020$

\title{
Semi real-time detection of subsurface consolidation defects during concrete curing stage
}

chongsheng cheng

University of Nebraska - Lincoln, cheng.chongsheng@huskers.unl.edu

Zhigang Shen

University of Nebraska - Lincoln, shen@unl.edu

Follow this and additional works at: https://digitalcommons.unl.edu/constructionmgmt

Digitadrt of the Construction Engineering and Management Commons, Structural Engineering Commons, GQmentmegsructural Materials Commons

Network

chgong, chongsheng and Shen, Zhigang, "Semi real-time detection of subsurface consolidation defects during concrete curing stage" (2020). Faculty Publications in Construction Engineering \& Management. 18.

https://digitalcommons.unl.edu/constructionmgmt/18

This Article is brought to you for free and open access by the Durham School of Architectural Engineering and Construction at DigitalCommons@University of Nebraska - Lincoln. It has been accepted for inclusion in Faculty Publications in Construction Engineering \& Management by an authorized administrator of DigitalCommons@University of Nebraska - Lincoln. 


\title{
Semi Real-time Detection of Subsurface Consolidation Defects during Concrete Curing Stage
}

\author{
Chongsheng Cheng ${ }^{1}$, and Zhigang Shen ${ }^{2}$
}

${ }^{1}$ Durham School of Architectural Engineering and Construction, University of Nebraska-Lincoln, 122 NH, Lincoln, NE 68588; e-mail: cheng.chongsheng@huskers.unl.edu

${ }^{2}$ Durham School of Architectural Engineering and Construction, University of Nebraska-Lincoln, 113 NH, Lincoln, NE 68588; e-mail: shen@unl.edu

\begin{abstract}
:
Subsurface consolidation defect is a common issue in concrete pavement construction, and the hidden defects often require costly repairs after project delivery. Therefore, being able to identify this type of defect during construction will enable contractor to conduct quick repairs to avoid costly postconstruction rework. In this paper a semi real-time detection approach using infrared thermography is introduced. The developed approach utilizes the hydration heat during curing time to identify the subsurface voids based on the regional temperature contrast. Experimental studies were conducted using artificial void-defect in different sizes and depths. The thermographic analysis is employed to locate the void-defects during the first 12 hours of curing time. The outcomes show that the defects are distinguishable within certain time windows during the curing process. In conclusion, infrared thermography can be used as a feasible and reliable non-destructive-detection method to conduct realtime or semi real-time monitoring of subsurface defects during concrete pavement construction.
\end{abstract}

Keywords: Subsurface Voids; Semi Real-time Detection; Regional Temperature Contrast; Thermographic Analysis; Non-uniform Thermal Background Estimation; NDT; and Concrete Hydration

\section{Introduction}

Subsurface voids (Fig.1) has been identified as a defect that could cause severe degradation of pavement performance. These small voids were found typically less than $10 \mathrm{~cm}$ (4 inches) in depth and $1.3 \mathrm{~cm}(1 / 2 \mathrm{inch})$ in gap width. During the pavement construction, situations such as improper vibration, overly dry mix, and/or long wait time between batches could cause the development of these void defects [1]. This type of consolidation issue has been constantly found in the highway pavement construction. However, there was no feasible method reported to detect these defects during construction stage. In general, the evaluation procedure of consolidation for pavement construction was recommended by the standard (ACI 309R) and the site quality control often relied on random sampling method [2]. The challenge to detect these voids during construction is that they were hidden from the visual inspection of the finishing surface. Therefore, being able to detect these voids as early as in the concrete initial setting will provide the opportunity for the field engineer to issue timely correction orders, which is more cost-effective than the repairment during service. 


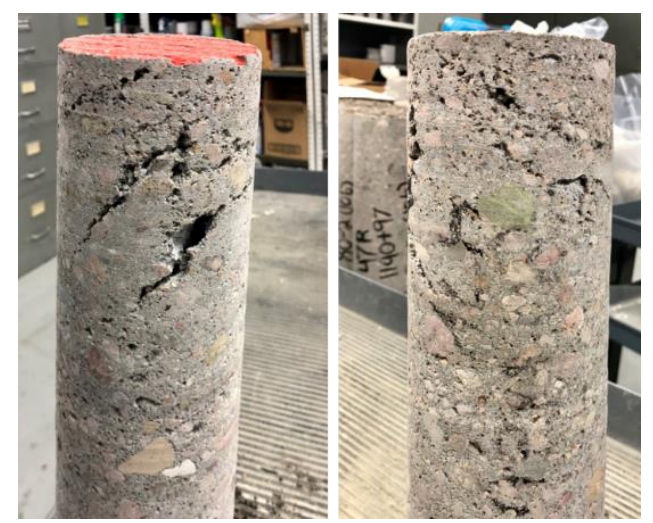

Figure 1. Sample cores provided by NDOT to show the voids found close to the surface in highway pavement

Previous studies on quality control for fresh concrete found in the literature concentrated on monitoring the vibration procedure. Minnich, Mawhorr, \& Schipper (1999) developed an accelerometer-based system to monitor the concrete consolidation based on the vibration rate of the vibrators array. This system provided a real-time display of each vibrator's vibration rate and alarmed the operator when the vibration signal below or above threshold limits. Cable, McDaniel, \& Steffes (1999) also reported that through monitoring and controlling the vibration rate, the consistency and the quality of concrete pavement could be improved. A visual monitoring system was developed [5,6] to record the position, depth, and duration of the vibrator in real-time. This system could assess the vibration effect and visualize the vibration defects to achieve the improvement of quality control during construction. Besides monitoring the status of the vibrator, the direct assessment of the fresh concrete was also studied. Alexander \& Haskins (1997) developed a device to measure the degree of consolidation through evaluating the change of electrical impedance value during the vibration. It found the curve of AC-resistance against the time of vibration was distinguishable for the entrapped air compared to the entrained air and argued the intersection of the two curves to be the indicator of consolidation completion. Although the previous studies put effort to ensure the consolidation quality through indirect monitorization, defects such as near-surface voids still exist in the current practice inevitably. Thus, the method that could directly detect this specific type of defect in an early stage of construction becomes valuable to address the problem. However, the early stage scanning of fresh concrete is challenging due to the plastic characteristic of concrete during the stages of hardening [8] which made the major contact-based methods become unavailable.

The infrared thermography (IRT) is a technique using infrared imager to sense irradiated heat from the object's surface. It has the advantage of fast scanning, large area of coverage, and noncontact nature as a nondestructive detection (NDT) method [9-11]. For the implementation of IRT for concrete structural NDT, the principle of detection relies on the developed temperature contrast between the defected and sound regions [12]. It has been developed for the delamination detection of concrete structures in experimental studies and field applications [9,11,13-16]. In general, the IRT for subsurface defects detection requires external heating passively or actively [15,17-19]. The halogen lamp was often used to actively control the heating procedure in experimental studies [18,19], while others took the advantage of solar heating in real-world investigation [20-22]. The studies that utilize the internally generated heat for defect detection were limited and a relevant study could be found by using the volumetric heating through microwave [23]. The induced heat due to the cement hydration of the fresh concrete made it a natural heating source, which could potentially be used for detecting the voids located at the near surface of the concrete pavement.

Earlier studies on the hydration of the fresh concrete revealed a large amount of heat released at the hardening stage [8] and a temperature distribution inside the concrete slab [24,25]. During the cement hydration, there are two stages that the concrete generates and releases the heat: hardening and cooling [8]. At the stage of hardening, the heat starts to generate right after the initial set and then continuous increase for hours (typically four to eight hours). Then at the cooling stage, the generated heat starts to drop for four to six hours. 
As illustrated in Fig.2, the temperature inside the slab is gradually decrease from the core location to the surface, where the boundary condition is dominated by the convection at the surface. As a result, the heat constantly flows outward from the core of the slab and a rapid temperature gradient would occur close to the slab surface (shown as red arrows in Fig 2). When a larger void or group of small voids occur at the near-surface (shown as a black box in Fig 2), they block the heat flow or/and change the thermal conductivity of the region so that it reduces the heat accumulation at the surface of the slab. Thus, the suspicious region would be shown as a cold region in the thermal image, where it can be evaluated through the temperature contrast [19].

This study introduces an early detection methodology using IRT to detect these defects based on the regional temperature contrast based on the basic thermal transfer principle illustrated in Fig. 2 .

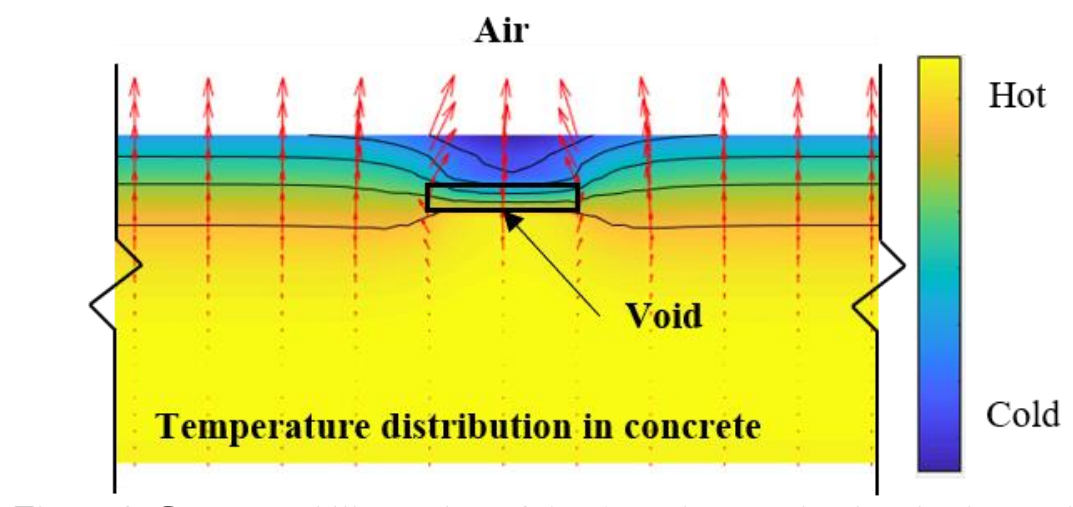

Figure 2. Conceptual illustration of the detection mechanism in the section view

\section{Experimental Method}

\subsection{Concrete Slab Casting}

Two concrete slabs were designed and prepared for the experiment (Fig.3). As shown in Table 1, the Styrofoam (Fig.4a) and spray foam (Fig.4b) were used to mimic the air voids due to the similar thermal conductivity (air: $0.024 \mathrm{~W} / \mathrm{m} \cdot{ }^{\circ} \mathrm{C}$, Styrofoam: $0.033 \mathrm{~W} / \mathrm{m} \cdot{ }^{\circ} \mathrm{C}$, spray foam: $0.024 \mathrm{~W} / \mathrm{m} \cdot{ }^{\circ} \mathrm{C}$ ). Slab 1 (Fig.3a) was designed to evaluate the effect of curing compound on thermal imaging. Three pairs of acritical voids were implanted in three depths side-to-side. Slab 2 (Fig.3b) was built to investigate the detectability and the optimal time window during the stages of hydration. Four groups of artificial voids were embedded. For each group, the void was embedded in the depth of $2.5 \mathrm{~cm}, 5.0$ $\mathrm{cm}, 7.6 \mathrm{~cm}$, and $10 \mathrm{~cm}$. The sides of both slabs were insulated by the formwork to imitate the condition of pavement construction. Table 2 shows the details of the slab dimension and mix designs. 


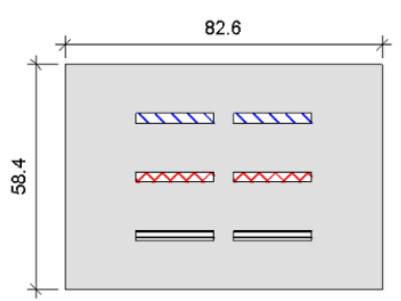

(a) Slab 1 \begin{tabular}{l}
11.1 Depth of $5.0 \mathrm{~cm}$ \\
\hline Depth of $7.6 \mathrm{~cm}$
\end{tabular} - Small Voids 2- Medium Voids 3- Oblong Voids 4- Compressed Air

(b) Slab 2

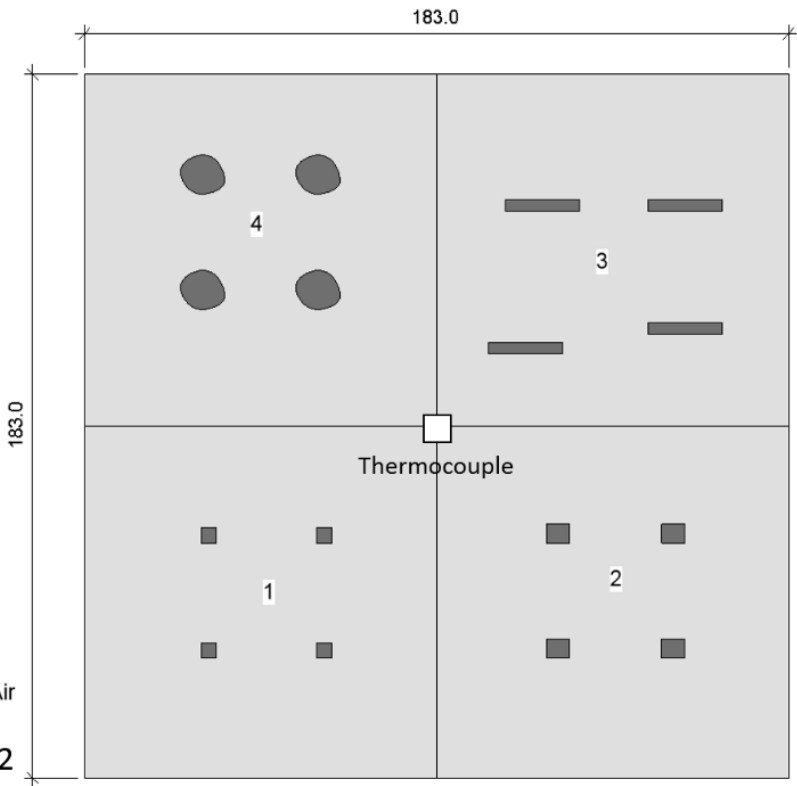

Figure 3. Detail of concrete slab design

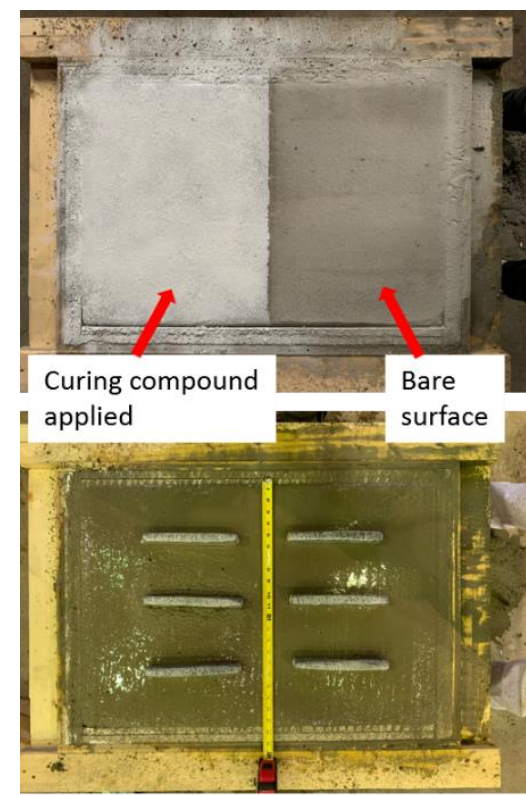

(a) Slab 1

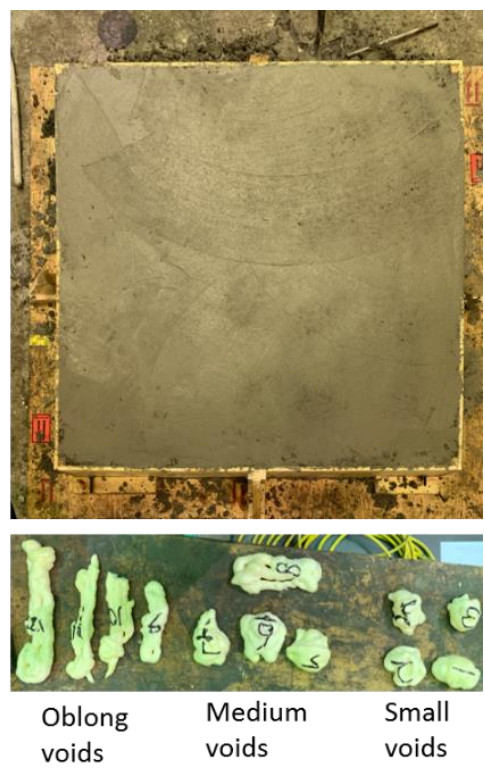

(b) Slab 2

Figure 4. Concrete slab construction

Table 1 details of voids

\begin{tabular}{|l|c|c|c|c|c|}
\hline Void details & Slab 1 & \multicolumn{4}{|c|}{ Slab 2* } \\
\hline Group & & 1 & 2 & 3 & 4 \\
\hline $\begin{array}{l}\text { Size } \\
(\mathrm{cm} \times \mathrm{cm} \times \mathrm{cm})\end{array}$ & $20 \times 3 \times 2$ & $5 \times 4 \times 1$ & $6 \times 4 \times 1$ & $15 \times 3 \times 1$ & N/A \\
\hline
\end{tabular}

*Note: the size in each group varied due to the production variation of spray foam

Table 2 details of the concrete slab

\begin{tabular}{|l|l|l|}
\hline Slab Details & Size $(\mathrm{cm})$ & Mix design \\
\hline Slab 1 & $82.6 \times 58.4 \times 30.5$ & Quickrete $^{1^{*}}$ \\
\hline Slab 2 & $183.0 \times 183.0 \times 22.9$ & $47 \mathrm{BD}^{2 *}$ \\
\hline
\end{tabular}

$1 *$ note: commercial pre-blended mix satisfying ASTM C387

2* note: typical mix design used for Nebraska highway pavement by NDOT 


\subsection{Experimental Procedure}

Fig.5 shows the setups and apparatus used in the experiments. The thermal camera (Fig.5b) was mounted on the top of the test slab for data collection. It was set to down facing the surface of the slab to ensure the quality of the collected data. The data was recorded every 30 seconds and then stored in the computer (Fig.5a) through FLIR ResearchIR software. Table 3 lists the detail specification of the thermal camera. During the experimentation, the temperature and humidity were recorded by the Tycon weather station at the 1-minute interval (Fig.5c).

The first experiment (on slab 1) was conducted indoor shown in Fig.5a. After the concrete was poured and consolidated, the artificial voids were implanted based on the design in Fig.3a and the exact layout is shown in Fig.4a. The curing compound (Right Pointe White Water Wax) was then applied in half of the finishing surface of the slab (Fig.4a). The data collection started from the surface applied curing compound and up to 72 hours. The first 48 hours' data was used for the later analysis. The second experiment (on slab 2) was carried out in the same laboratory at the indoor conditions. After the concrete was finished and the artificial voids were embedded, the curing compound was applied on the entire surface. The data were continuously recorded from the surface finishing up to 20 hours. During the time from $3^{\text {rd }}$ to $5^{\text {th }}$ hours after concrete pour, the bottom half of the slab was covered by a plastic sheet for group penetration radar (GPR) scanning. All recorded thermal images were then processed in the later section for thermographic analysis. Aside from the data collected by the thermal camera, a thermocouple implanted in the center of the slab in $4 \mathrm{~cm}$ deep was used to record the temperature every 15 minutes.

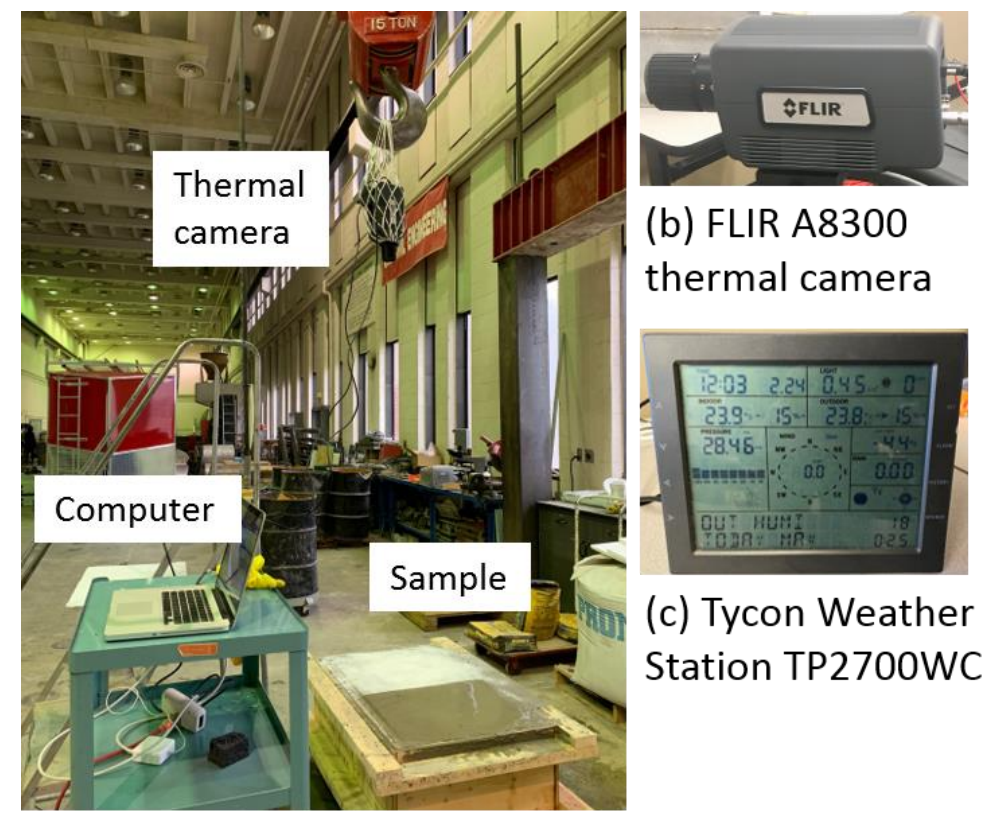

(a) Experimental setup

Figure 5. Detail of experimental setups and apparatus

Table 3 thermal camera specification

\begin{tabular}{|l|c|c|c|c|c|}
\hline $\begin{array}{l}\text { Thermal } \\
\text { Camera }\end{array}$ & $\begin{array}{l}\text { Spectral } \\
\text { Range }\end{array}$ & $\begin{array}{l}\text { Spatial } \\
\text { Resolution }\end{array}$ & $\begin{array}{l}\text { Thermal } \\
\text { Sensitivity at } \mathbf{2 5}^{\circ} \mathbf{C}\end{array}$ & $\begin{array}{l}\text { Temperature } \\
\text { Sensing Range }\end{array}$ & $\begin{array}{l}\text { Max Frame Rate } \\
\text { at Full Resolution }\end{array}$ \\
\hline FLIR A8300 & $3 \sim 5 \mu \mathrm{m}$ & $1280 \times 720$ & $20 \mathrm{mk}$ & $-20^{\circ} \mathrm{C} \sim 350^{\circ} \mathrm{C}$ & $60 \mathrm{~Hz}$ \\
\hline
\end{tabular}

\section{Thermographic Analysis}

\subsection{Measurement Calibration}

To normalize the environmental effects on the thermographic analysis, several parameters need to be calibrated for the thermal imaging system. The measured temperature of the object relies 
on the received thermal radiation by the camera, which is affected by the object surface emissivity, distance, atmospheric temperature and transmission, and relative humidity [26]. As shown in Table 4, for each experiment, the distance between slab and camera, ambient temperature, and humidity were recorded. The reflected temperature and optics temperature were estimated by using ambient temperature [26] shown in Fig.6b. The relative humidity was directly reading from the weather station. The estimation of the object's surface emissivity was simplified and the general value of 0.95 was used for the dry concrete surface. The inaccurate estimation of the emissivity will affect the measurement of absolute temperature while the detectability of a thermal pattern is dependent on the temperature contrast. Thus, how the contrast varies plays an essential role in the evaluation. As a result, in the later section, a series of post-processing for the raw thermal image is proposed to normalize the effects caused by the measurement bias and other found noise such as the non-uniformity in the background temperature.

Table 4 detail of parameters for calibration

\begin{tabular}{|c|l|c|l|c|c|c|c|}
\hline Experiment & $\begin{array}{l}\text { Object } \\
\text { Surface } \\
\text { Emissivity }\end{array}$ & $\begin{array}{l}\text { Object } \\
\text { Distance }(\mathrm{m})\end{array}$ & $\begin{array}{l}\text { Object } \\
\text { Reflected } \\
\text { Temperature }\end{array}$ & $\begin{array}{l}\text { Atmospheric } \\
\text { Temperature }\end{array}$ & $\begin{array}{l}\text { Relative } \\
\text { Humidity }\end{array}$ & $\begin{array}{l}\text { Optics } \\
\text { Temperature }\end{array}$ & $\begin{array}{l}\text { Optics } \\
\text { transmission }\end{array}$ \\
\hline Slab 1 & 0.95 & 1.9 & $\mathrm{a}^{*}$ & $\mathrm{a}^{*}$ & $\mathrm{~b}^{*}$ & $\mathrm{a}^{*}$ & 1 \\
\hline Slab 2 & 0.95 & 4.6 & $\mathrm{a}^{*}$ & $\mathrm{a}^{*}$ & $\mathrm{~b}^{*}$ & $\mathrm{a}^{*}$ & 1 \\
\hline
\end{tabular}

$\mathrm{a}^{*}$ note: using ambient temperature collected by weather station

$b^{*}$ note: using relative humidity collected by weather station

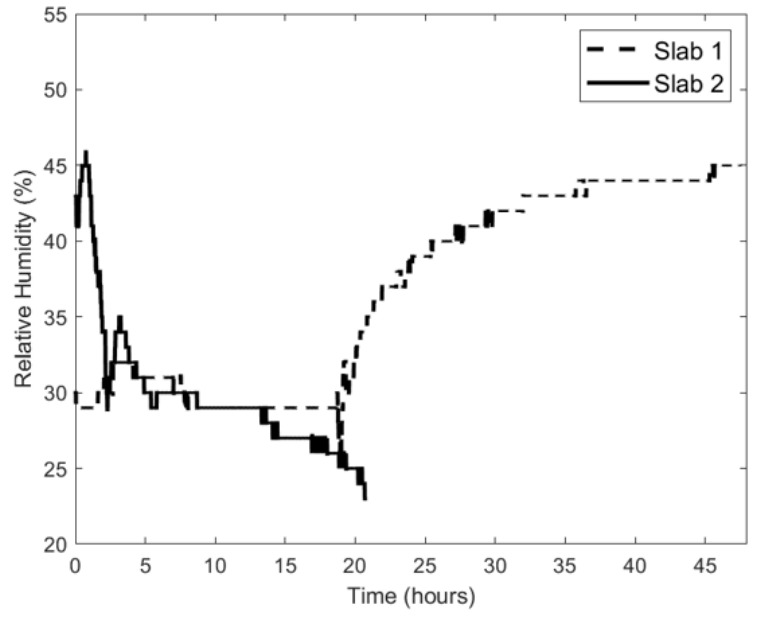

(a) Relative humidity

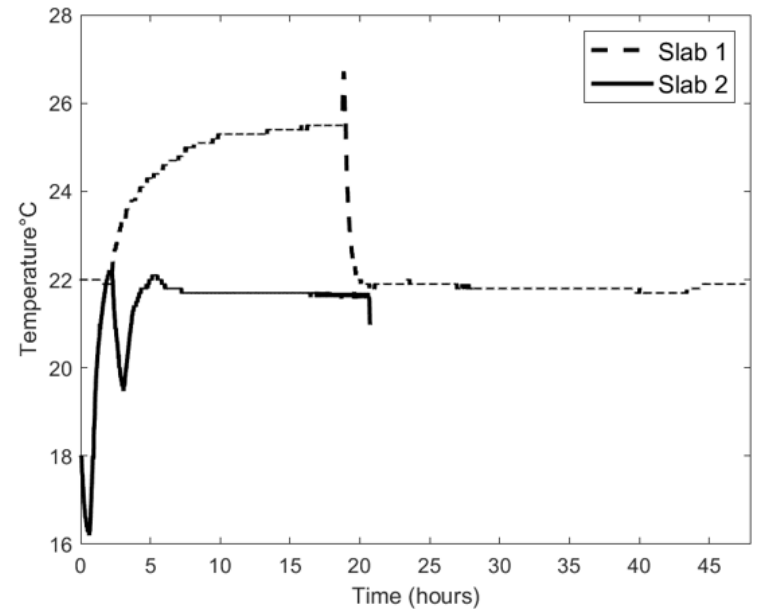

(b) Ambient temperature

Figure 6. Ambient temperature and relative humidity recorded by weather station

\subsection{The Procedure of Thermographic Analysis}

As shown in Fig.7, the proposed have three major procedure: background estimation, contrast generation and normalization, and regional-minima extraction. In the module of background estimation, the thermal raw image is firstly screened by reducing the spatial outliers. These outliers often are the sparkling points in the image caused by reflected IR light, whose numeric values are much higher than the realistic measurement. We identify them by finding the value larger than three standard deviations $\left(\sigma_{3}\right)$ in a small local region. The assumption is that within a small area, the temperature variation is expected low. This step could be achieved in Eq. (1) by finding the outlier points in the subtraction of the raw image from mean filtered image $\left(m_{(5,5)}\right)$. Then the values of the found outliers are replaced by their nearest neighbors. Besides the existing outliers in the thermal image, the non-uniform background was another phenomenon often observed in thermographic processing for concrete structures [16,27]. This non-uniformity could be estimated by using median filtering [28] so that the background image $\left(T_{\text {background }}\right)$ could be generated. The background image estimates the temperature of each point through looking at the median of its neighbors. The underlaid assumption is the non-uniformity of the temperature distribution across the entire slab surface is much 
smoother than the one caused by the defect's abnormality locally. As a result, we used the $1 / 4$ of the shorter-side length of the image as the median filter size through Eq. (2).

$$
\begin{aligned}
& T_{\text {outlier }}=T_{i} \mid i \in i>\sigma_{3}\left(T_{\text {raw }}-m_{(5,5)}\left(T_{\text {raw }}\right)\right) \\
& T_{\text {background }}=\text { median_filter }{ }_{\left(\frac{1}{4} l, \frac{1}{4} l\right)}\left(T_{\text {outlier }}\right)
\end{aligned}
$$

To evaluate the detectability of the defect along with the duration of hydration, the contrast image ( $\left.T_{\text {contrast }}\right)$ is then generated based on [29] shown in Eq. (3). Each point in the contrast image represents the temperature difference compared to its background correspondingly. Normalizing the contrast image at each time window by Eq. (4) can make the evaluation consistently along with the duration of hydration. Once the contrast value has been evaluated, the threshold values can be determined to extract the potential defected area, which can be used as a criterion for detectability.

$$
\begin{aligned}
T_{\text {contrast }} & =T_{\text {raw }}-T_{\text {background }} \\
T_{n} & =\frac{T_{\text {contrast }}-T_{\min }}{T_{\max }-T_{\min }}
\end{aligned}
$$

In the last module, the visualization is enhanced by using the selected threshold through regional-minima extraction, which is designated to support the decision making for the field engineer. The theory of the extraction is based on the solitary behavior of the observed defect abnormality in the thermal image according to the author's previous work [11]. These isolated regions could be treated as local minima and extracted by morphologic operations [30]. In Eq. (5), the extraction image ( $T_{\text {extracted }}$ ) suppresses the area where have the value larger than the threshold $\boldsymbol{H}$. As a result, the areas shown as local minima are preserved and the others in the image are set to zero (shown as white in Fig.8d). This final step aims to improve the visualization of the detection which is useful to clear up the result for the imaging-based technologies. It also preserves the variational information in the regions segmented (the intensity of blackness varies in Fig.8d). Fig. 8 shows the intermediate results of the thermographic analysis correspondingly.

$$
T_{\text {extracted }}=T_{n}-H_{\text {minia }}\left(T_{n}, H\right)
$$

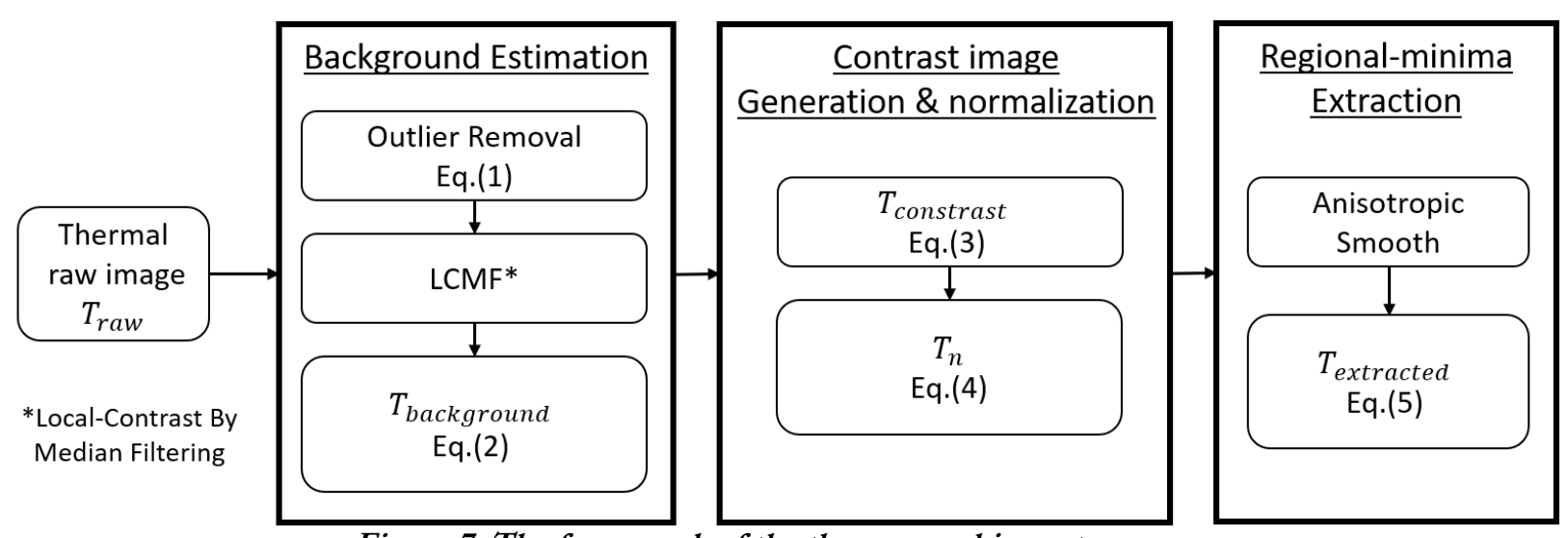

Figure 7. The framework of the thermographic post-process 


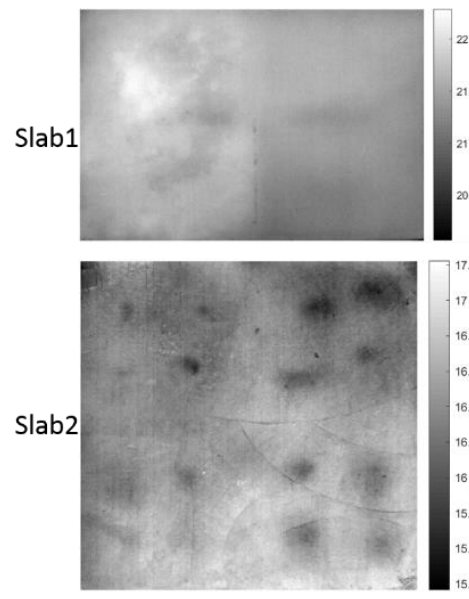

(a) $T_{\text {raw }}$
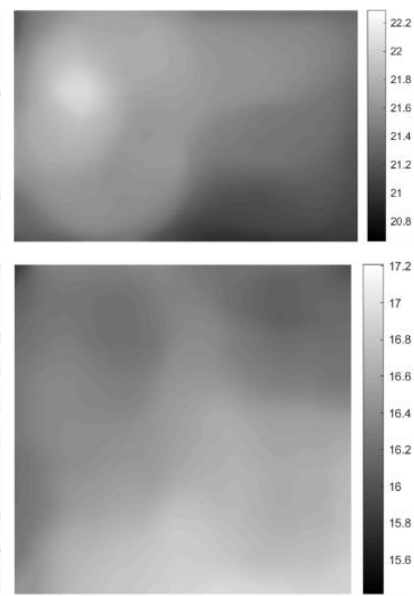

(b) $T_{\text {background }}$

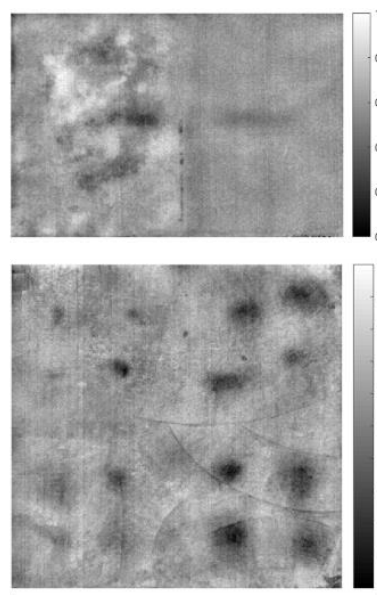

(c) $T_{n}$
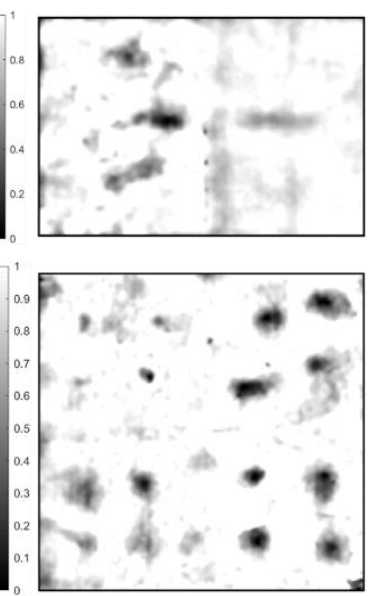

(d)extraction

Figure 8. The intermediate results of the proposed framework. (a) raw thermal (Unit: ${ }^{\circ} \mathrm{C}$ ), (b) estimated background image (Unit: $\left.{ }^{\circ} \mathrm{C}\right),(\mathrm{c})$ normalized contrast image (non-unit, range $\left.0 \sim 1\right)$, (d) extracted voids by the threshold of 0.3 in $T_{n}$.

\subsection{The Procedure of Evaluation}

To measure the feasibility of detection, the analysis is conducted by evaluating the numerical values of the areas above the embedded voids in the slabs along time. To evaluate the effects of implanting depth and the sprayed curing compound (Fig.9a), the area for each void under the bare and cure surfaces is determined shown as a solid rectangle. The reference is then selected at the nearby locations shown as a dashed rectangle. To investigate the effect of sizes (Fig.9b), only one defected area is selected in the groups of 1 to 3 . The selection was based on the reading from the ground penetration radar (GPR) scans, which showed all three selected defects located at the same depth around $3 \mathrm{~cm}$ from the surface. The mean value of each rectangle is used for quantitative analysis. For each selected area shown in Fig.9, the absolute contrast $C_{a b s}$ represents the value from the image $T_{\text {contrast }}$ indicating the absolute temperature difference. The normalized contrast $C_{n}$ obtained from the image $T_{n}$. The $\Delta C$ in Eq. (6) calculates the difference of defected ( $C^{\text {defect }}$ ) to the reference area $\left(C^{r e f}\right)$.

$$
\Delta C=C^{\text {defect }}-C^{r e f}
$$

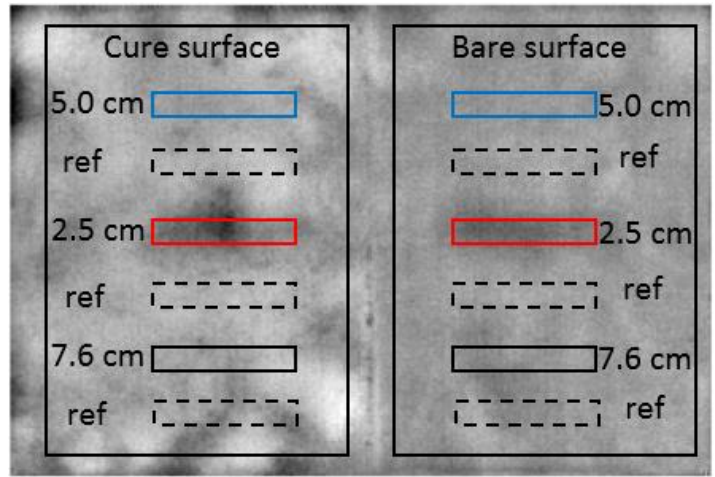

(a) Evaluation of slab 1

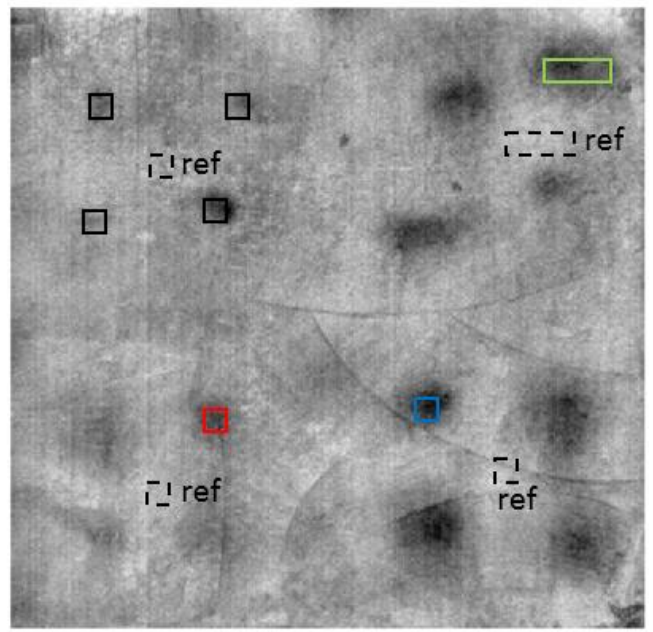

(b) Evaluation of slab 2

Figure 9. Evaluation procedure 


\section{Results}

\subsection{The Feasibility of Detection by $C_{a b s}$}

As shown in Fig.10, the areas (defined in Fig.9) present negative temperatures contrasts, meaning that the temperature of the defected areas is lower than the surroundings. For the temperature contrast in the area whose surface is not applying the curing compound (bare surface in Fig.10a), it starts to increase at the $5^{\text {th }}$ hour and reaches the maximum at the $12^{\text {th }}$ hour with the value of -0.2 for the void in $2.5 \mathrm{~cm}$ deep (red solid line). The contrasts for voids in $5 \mathrm{~cm}$ deep (blue solid line) and $7.6 \mathrm{~cm}$ deep (black solid line) are developed less than -0.05 at the time between $15^{\text {th }}$ to $20^{\text {th }}$ hour. The reference (black dash line) shows a varied contrast level between 0 and 0.05 from time to time. For the temperature contrast in the area with sprayed curing compound (cure surface in Fig.10b), the void at $2.5 \mathrm{~cm}$ deep develops the maximum contrast of -0.3 at the $12^{\text {th }}$ hour while the void in 5 $\mathrm{cm}$ deep has maximum contrast of -0.06 at the $5^{\text {th }}$ hour and the void in $7.6 \mathrm{~cm}$ deep presents the contrast above zero. The reference in this area has a contrast level from 0 to 0.1 depending on time. In summary, a trend is observed that the contrast will increase and then decrease along with the hydration. The curing compound tends to increase the maximum contrast for the void in $2.5 \mathrm{~cm}$ deep while decrease contrast value and interrupts the trend for the deeper voids.

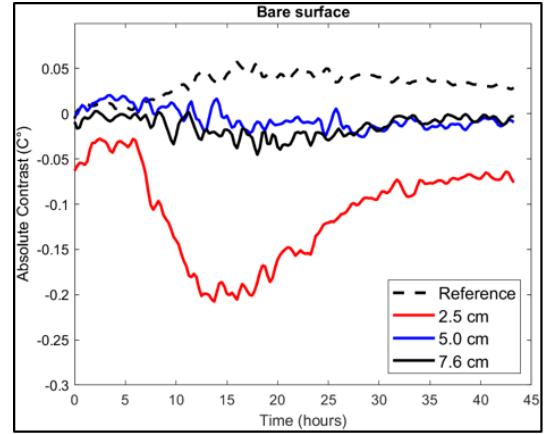

(a)

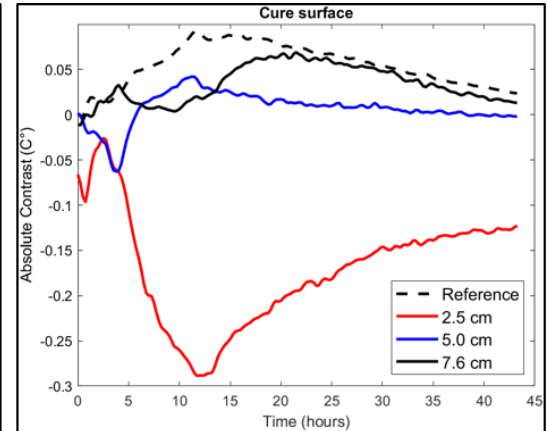

(b)

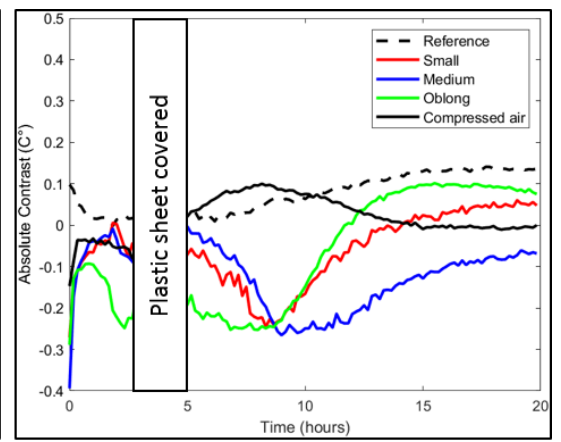

(c)

Figure 10. Results of absolute contrast $\left(C_{a b s}\right)$ : (a) bare surface of slab 1, (b) cure surface of slab 1, (c) slab 2.

Fig.10c shows the results of slab 2 where the effect of the size difference is evaluated. Since the plastic sheet was covered from the $3^{\text {rd }}$ hour to the $5^{\text {th }}$ hour, the data were not analyzed during that period. Fig.11a shows the absolute contrast of the selected areas. The void with oblong shape (green solid line) has the absolute contrast of -0.3 at the $0^{\text {th }}$ hour right before the curing compound is applied. Then the contrast decreases to -0.1 at the $1^{\text {st }}$ hour. Thereafter, it starts to increase and reach the maximum value of -0.25 after two and a half hours. This contrast lasts to the $8^{\text {th }}$ hour and decreases thereafter. The void with small size (red solid line) has a contrast of -0.27 at the beginning and then decreases to less than -0.05 at the $1^{\text {st }}$ hour. After 5 hours, it starts to increase and reaches a maximum of -0.25 at the $8.5^{\text {th }}$ hour. The void with a medium size (blue solid line) starts with the contrast of 0.39 and then decreases to less than -0.05 at the $1^{\text {st }}$ hour. It also starts to increase after 5 hours and reaches -0.26 at the $9^{\text {th }}$ hour. The defect stimulated by compressed air (black solid line) starts with a contrast of -0.15 at time zero and decreases to less than -0.05 after 20 minutes. This contrast lasts to the $3^{\text {rd }}$ hour and becomes positive after $5^{\text {th }}$ hour and then decreases toward zero after. This shows the average contrast for this type of defect does not have a similar trend pattern than the other three groups. The reference (black dash line) contrast varies between 0 to 0.1. Based on the previous analysis of absolute contrast, it shows the agreement in results with the first slab that the void defect presents a negative temperature contrast in the thermal image. It also reveals that the size difference does not contribute much difference in the absolute contrast $(-0.2)$ while the longer void can reach the maximum contrast at an earlier time.

\subsection{The Evaluation of Detection by $C_{n}$}

Fig.11 shows the results of normalized contrast for the same areas in Fig.10. The contrast image $\left(T_{\text {contrast }}\right)$ at each time window is rescaled to the range from 0 to 1 . In the bare surface (Fig.11a), 
the normalized contrast for the void (red solid line) in $2.5 \mathrm{~cm}$ deep rapidly changes from the $0^{\text {th }}$ hour to the $4^{\text {th }}$ hour and then becomes stable staying at the contrast level of 0.4 after the $9^{\text {th }}$ hour. For the voids in $5 \mathrm{~cm}$ (blue solid line) and $7.6 \mathrm{~cm}$ (black solid line) deep, they present a stable contrast level of 0.65 started from the $5^{\text {th }}$ hour. The reference (black dash line) contrast level is not distinguishable to deeper voids ( $5 \mathrm{~cm}$ and $7.6 \mathrm{~cm}$ deep) until the $10^{\text {th }}$ hour and then becomes distinguishable with the value of 0.75 . Compared to the cure surface (Fig.11 b), the void in $2.5 \mathrm{~cm}$ deep reaches the contrast level of 0.3 at the $8^{\text {th }}$ hour while the void in $5 \mathrm{~cm}$ deep has the contrast level of 0.65 at the $6^{\text {th }}$ hour. The void in $7.6 \mathrm{~cm}$ deep presents a stable contrast level of 0.75 after the $15^{\text {th }}$ hour. The reference shows a varying contrast level before the $15^{\text {th }}$ hour and roughly a consistent value of 0.75 after. In summary, the normalization regularizes the contrast variation along time to some degrees which makes it possible to use constant values to distinguish the defect from sound regions at a certain range of time window.

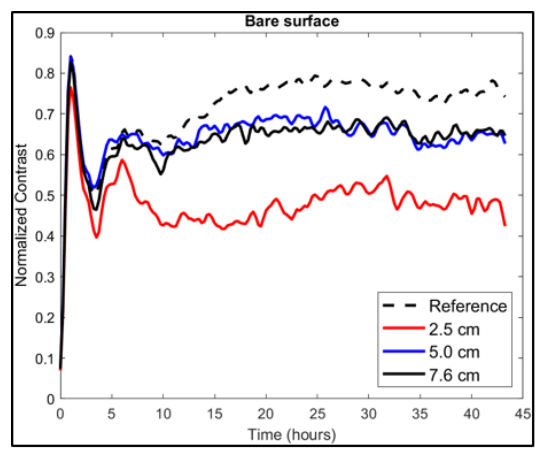

(a)

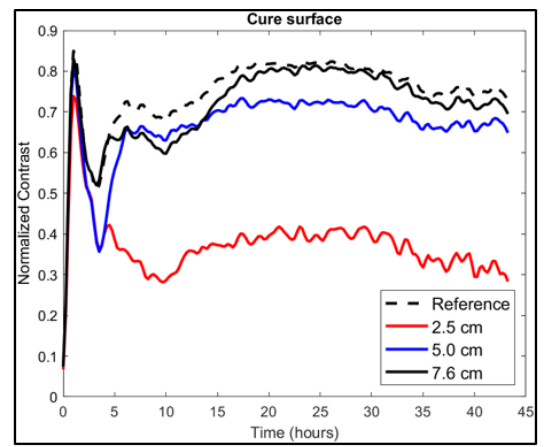

(b)

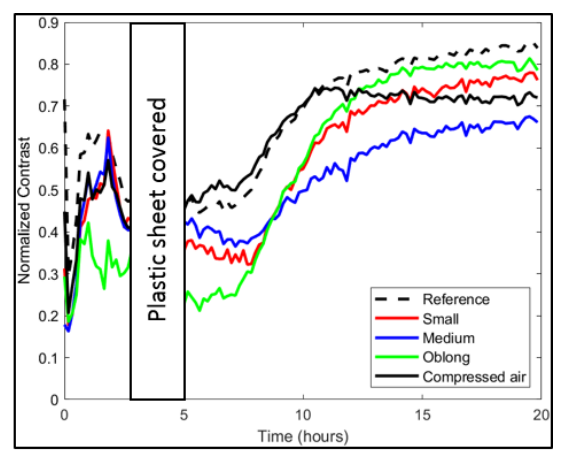

(c)

Figure 11. Results of normalized contrast ( $\left.C_{n}\right)$ : (a) bare surface of slab 1, (b) cure surface of slab 1, (c) slab 2.

Fig.11c shows the results of the normalized contrast level $\left(C_{n}\right)$ from slab 2. For the defect with oblong shape (green solid line), the normalized contrast level is 0.3 at the $0^{\text {th }}$ hour and ranges from 0.3 to 0.4 from time $30^{\text {th }}$ minute to $3^{\text {rd }}$ hour. It stays between 0.2 and 0.3 from the $5^{\text {th }}$ to the $7^{\text {th }}$ hour and starts to increase gradually to 0.8 at the $14^{\text {th }}$ hour and becomes stable after. The defect with small size (red solid line) has the normalized contrast level of 0.3 at the $0^{\text {th }}$ hour and ranges between 0.4 and 0.6 from $30^{\text {th }}$ minute to $3^{\text {rd }}$ hour. It stays from 0.3 to 0.4 between the $5^{\text {th }}$ and $8^{\text {th }}$ hour and increases to 0.75 gradually thereafter. The defect in the medium size (blue solid line) starts with the normalized contrast level of 0.18 and varies between 0.4 and 0.6 from the $30^{\text {th }}$ minute to the $3^{\text {rd }}$ hour. It stays from 0.37 to 0.43 between the $5^{\text {th }}$ and $8^{\text {th }}$ hour and increases to 0.67 gradually thereafter. The defect made by compressed air shows 0.45 in normalized contrast at the $0^{\text {th }}$ hour and varies between 0.4 and 0.6 from the $30^{\text {th }}$ minute to the $3^{\text {rd }}$ hour. Starting at $5^{\text {th }}$ hours it increases to 0.74 at the $10^{\text {th }}$ hour and then decreases to 0.72 after. The reference level (black dash line) starts at 0.72 at the $0^{\text {th }}$ hour and ranges between 0.5 and 0.64 from the $30^{\text {th }}$ minute to the $3^{\text {rd }}$ hour. It then increases to 0.84 gradually after the $5^{\text {th }}$ hour. In summary, the normalization decreases the contrast variations of the voids between the $30^{\text {th }}$ minute and the $8^{\text {th }}$ hour compared to the absolute contrast. It also reveals the larger void develops lower normalized contrast levels (0.3) than smaller voids (0.4). However, a rapid change of contrast levels occurs after the $8^{\text {th }}$ hour and the contrast level tends to reverse after the $10^{\text {th }}$ hour. This shows that using the normalized contrast value to indicate the depth of the void is not stable and consistent enough across the entire period of hydration.

Although the feasibility of detection is revealed and evaluated by the analysis of contrast, the factors such as ambient temperature variation and the non-uniformity of curing compounds having potential effects on detection need to be discussed.

\subsection{The Visualization of Detection using $T_{\text {extracted }}$}

Once subtracting the reference area from the defected area in the normalized contrast $\left(C_{n}\right)$, the threshold value $\boldsymbol{H}$ (in Eq.5) can be reviewed and then visualization of the detection image can be generated by extracting these areas. Based on the discussion of the threshold selection in Section 5.4, 
and the nature of the proposed method in Eq. 5, an empirical value of 0.3 is used for both slabs for visualization of detection. As shown in Fig.12, the shallowest voids ( $2.5 \mathrm{~cm}$ deep) are clearly presented in both bare (right-hand side) and cure (left-hand side) surfaces. The voids in 5 and $7.6 \mathrm{~cm}$ deep shows strong contrast only at the $4^{\text {th }}$ hour with irregular shapes in the cure surface. The void in 5 and $7.6 \mathrm{~cm}$ deep in the bare surface become visually distinguishable at around the $18^{\text {th }}$ hour but showing lower contrast compared to the one in $2.5 \mathrm{~cm}$ deep.
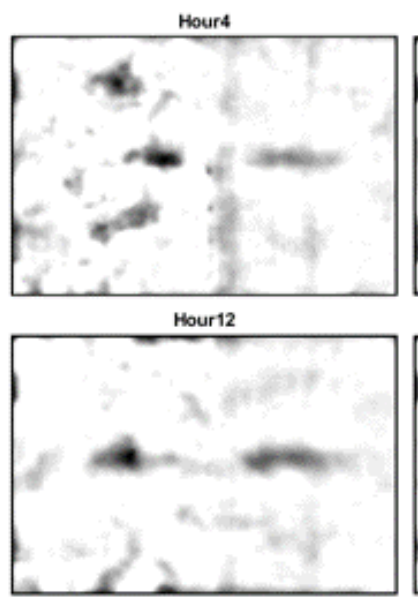

Hour20

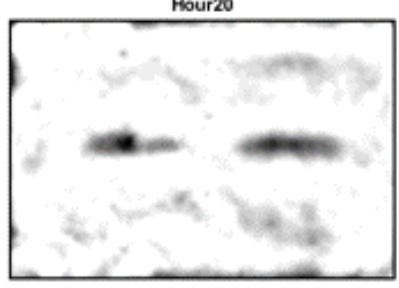

Hour28

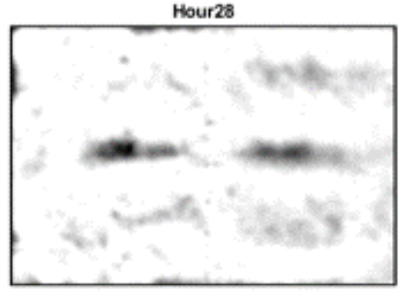

Hour36

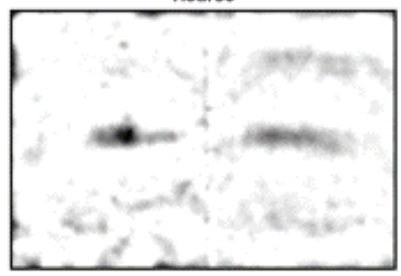

Figure 12. Results of vis

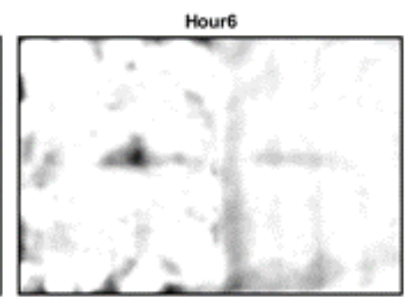

Hour14

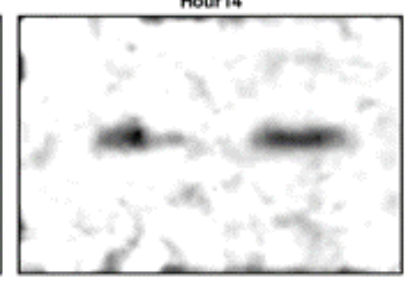

Hour22

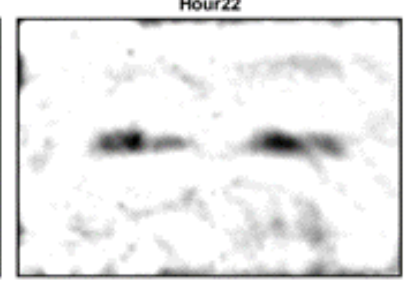

Hour30

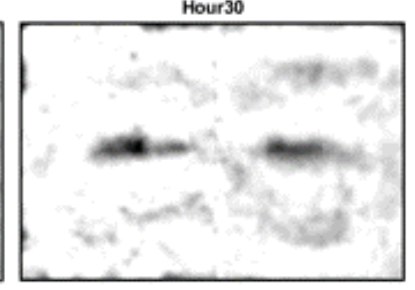

Hour38

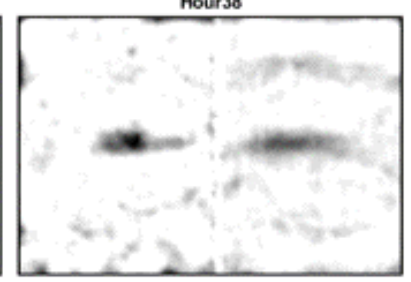

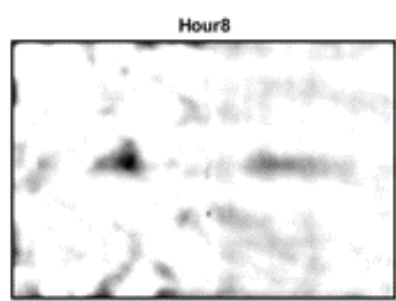

Hour16
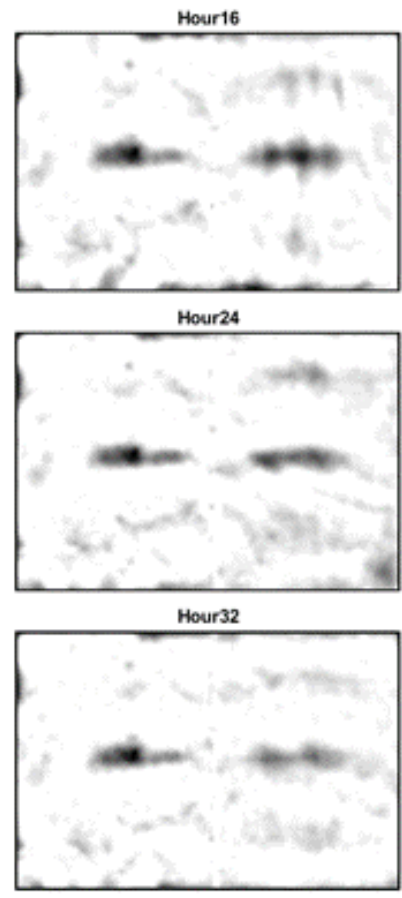

Hour40

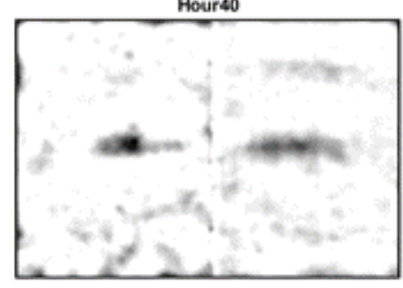

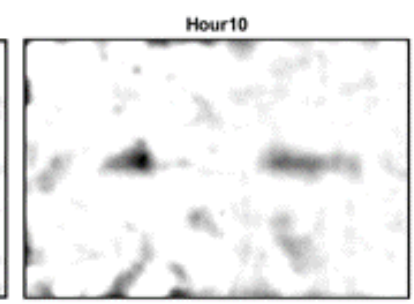

Hour18

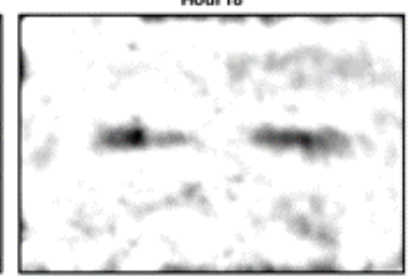

Hour26
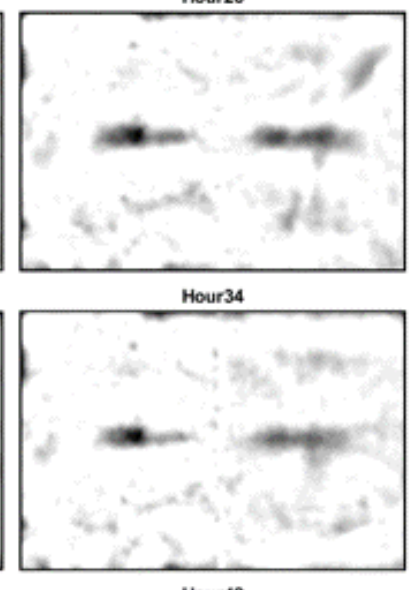

Hour42

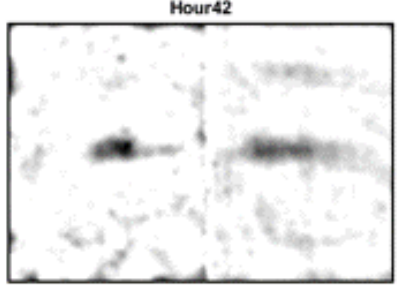

isualization for slab 1: images started on $4^{\text {th }}$ hour which is the observed start of the hardening stage.

Fig.13 shows the visualization results of the second slab. At the $0^{\text {th }}$ hour, it clearly shows all artificial defects before the time that the curing compound was applied. Between $1^{\text {st }}$ hour and $2^{\text {nd }}$ hour, the visibility is decreased and only defects with oblong shape remain distinguishing. After the $5^{\text {th }}$ hour, the visibility of all defects starts to increase and remains visually identifiable until the $9^{\text {th }}$ hour. After the $9^{\text {th }}$ hour, the contrast decreases. Based on the result of the two slabs, the visualization shows the consistent agreement of visibility to the normalized contrast level in Fig.11. It also supports that a single constant value could be used as a threshold to distinguish the defect during a certain period of hydration. 

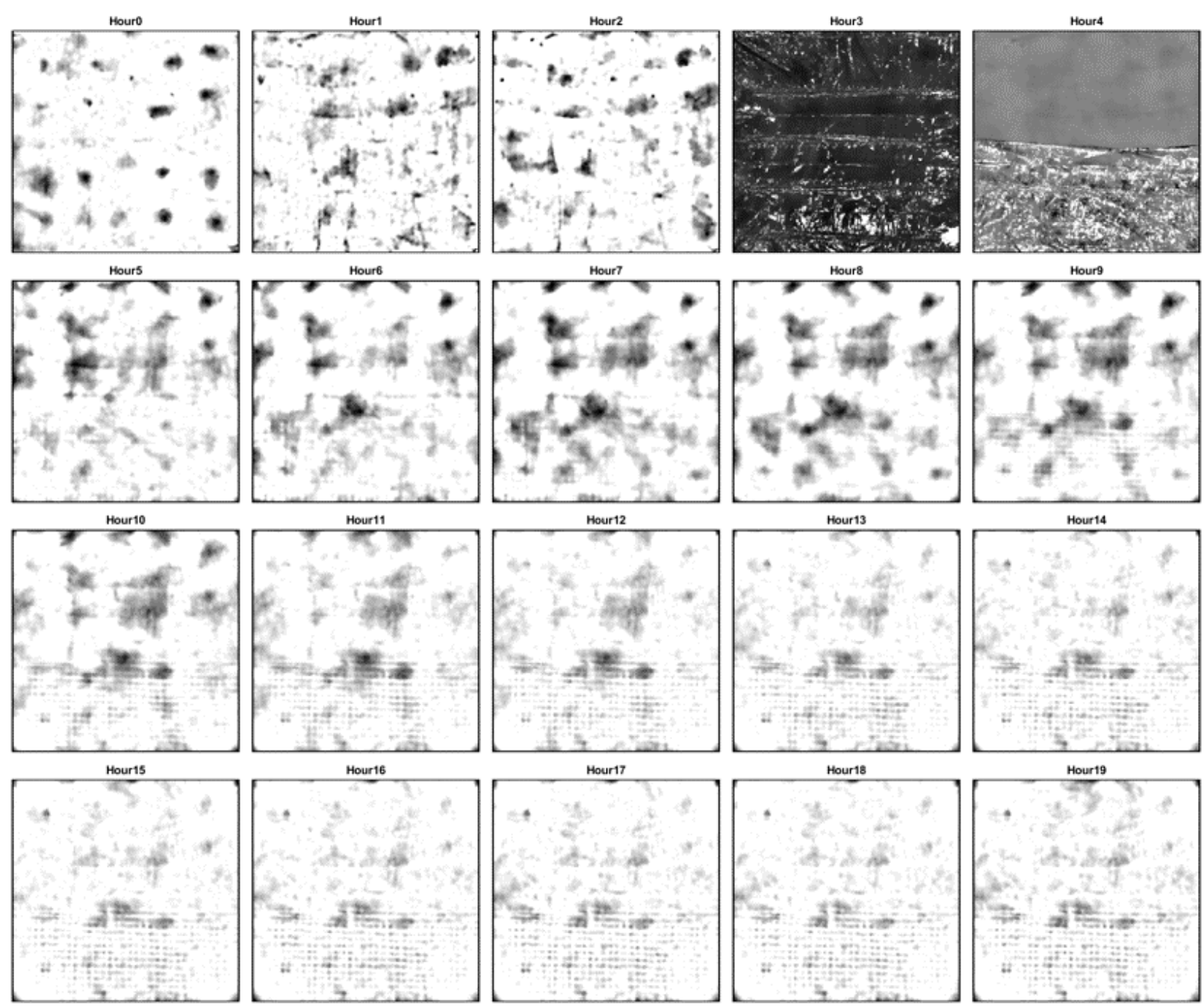

Figure 13. Results of visualization for slab 2: images started at the last moment before the curing compound was applied.

\section{Discussions}

\subsection{Effects of Ambient Temperature}

As shown in Fig.14, the ambient temperature demonstrates a reciprocal effect on the development of contrast. For both slabs, the absolute temperature contrast decreases (towards zero) as the ambient temperature increases. As long as the ambient temperature becomes stable, the development of contrast is dominated by the development of the heat generated by the hydration (indicated by concrete temperature rising in Fig.14 shown as surface temperature and thermocouple reading). It also finds that the larger void has greater sensitivity to the ambient temperature change. Comparing Fig.14c to Fig.14e, the small size void (red line in Fig.14c) does not show a contrast increase after ambient temperature drops at the $2^{\text {nd }}$ hour. The medium size void (blue line in Fig.14d) shows a slight increase of contrast while the oblong void (green line in Fig.14e) shows a large increase of contrast. The explanation could be revealed by the conceptual mechanism illustrated in Fig. 2 that the contrast development is assumed based on the heat flow from the concrete core to surface and then releases to the ambient. This process requires the temperature in the core location is higher than the one on the surface where the heat is exchanged by convection. When the ambient temperature increases and is higher than the surface temperature, the direction of heat flow between air and concrete surface is reversed. As a result, the contrast of the void will decrease due to the lack of dominance of heat flow in the perpendicular direction [31]. However, the quantitative evaluation of this effect needs further investigation. 


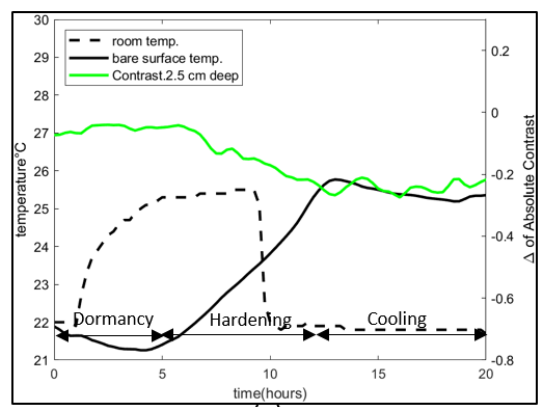

(a)

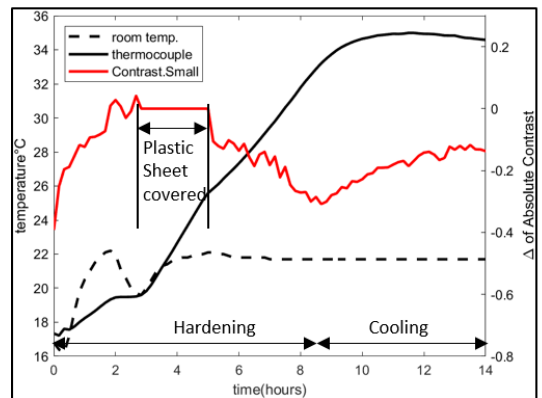

(c)

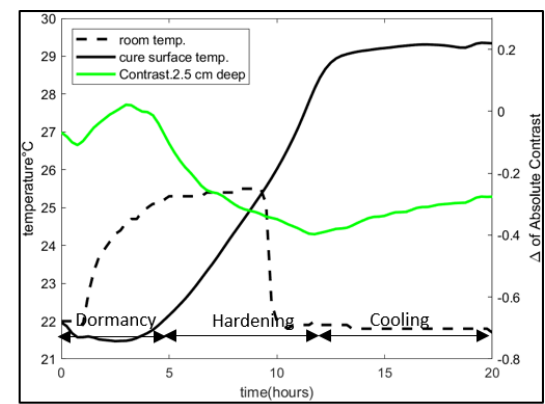

(b)

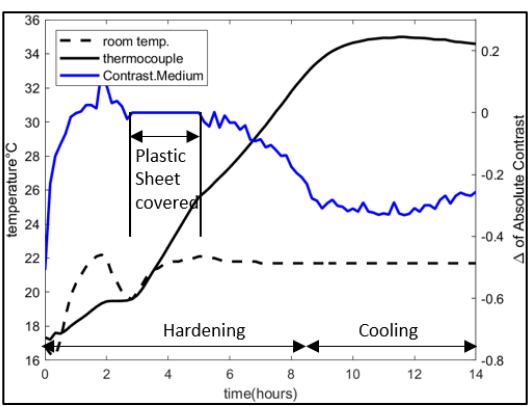

(d)

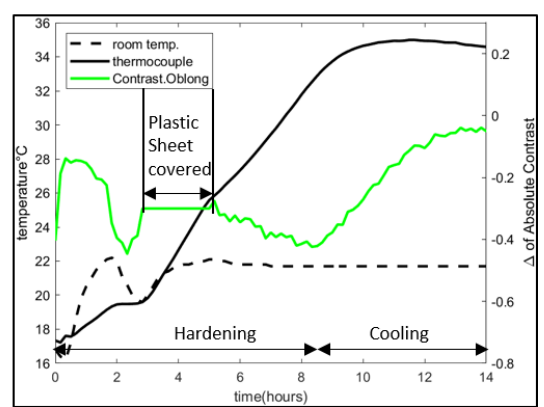

(e)

Figure 14. Effects of ambient temperature on absolute contrast and time window of detection (all voids are around $2.5 \mathrm{~cm}$ deep): (a) void in the bare surface of slab 1; (b) void in cure surface of slab 2; (c) small size void in slab 2; (d) medium size void in slab 2; and (e) oblong void in slab 2. The calculated surface temperature is used to indicate the stages of hydration for slab 1 and the thermocouple reading is used to indicate the stages of hydration for slab 2.

\subsection{Time Window for Detection}

Based on the experimentations on two different concrete slabs, the optimal window could be suggested within two stages in the hydration: the later hardening and early cooling. From Fig.14, it observes that the larger sized void starts to develop the detectable contrast at an earlier time than smaller voids. The contrast will decrease in the cooling stage for all voids with different sizes. Besides this range of time window, another time window for slab 2 occurs at the early time in the hardening stage before the curing compound is applied $\left(0^{\text {th }}\right.$-hour image in Fig.13). However, this time window does not occur during the experiment on slab 1 . The potential explanation might be the different mix designs of the two slabs. Thus, this emergent time window is undetermined which needs further investigations.

\subsection{Visual Effects of Sprayed Curing Compound}

Although the effect was discussed quantitatively in the previous section, the curing compound may introduce noises in the result visualization as shown in Fig.15. Firstly, applying the curing compound unevenly brings irregular patterns in the thermal image. These patterns often are caused by the non-uniform thickness of the curing compound, which makes the shape of the void become distorted (comparing the void in cure surface to the bare surface in Fig.15a). Secondly, when the curing compound is just applied and wet, the moisture masks the surface which makes it unfavorable for detection. In summary, the curing compound brings variations in the contrast visualization and thus degrades the detectability. On the other hand, it may help to develop the contrast of void at the later stage of hardening served as the isolation layer on the top of the concrete surface found in section 4.1. 


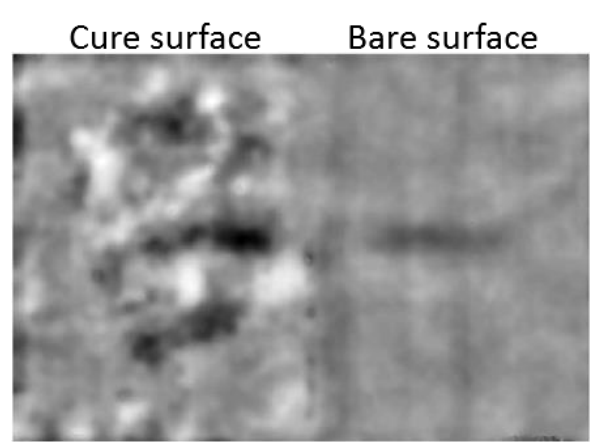

(a)

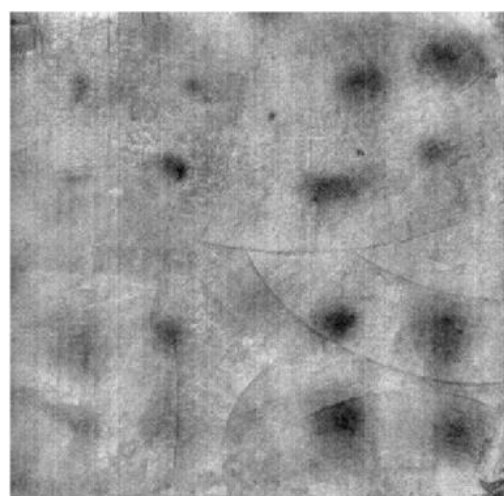

(b)

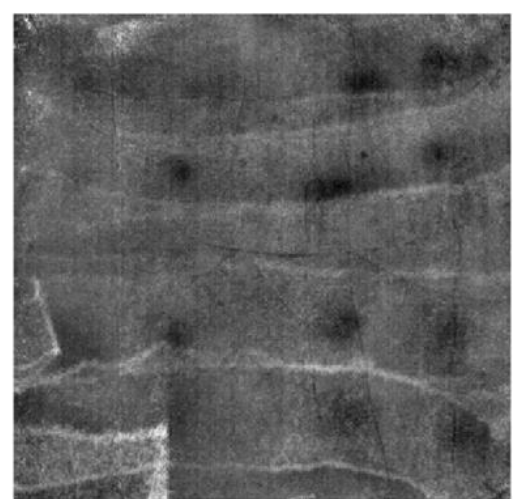

(c)

Figure 15. Visual effects of sprayed curing compound: (a) slab 1 at $4^{\text {th }}$ hour of hydration; (b) the last frame before curing compound is applied; and (c) right after the curing compound is applied.

\subsection{Considerations in Practice and Limitations}

There are several considerations and limitations need to be discussed in the current study. First, the environmental variations on the field will bring more uncertainties than the controlled environment in the experiment. Since the ambient temperature and the application of the curing compound have been found as factors to impact the detectability, the outdoor conditions need to be investigated how these factors can be affected in detail. For example, the effects of solar heating and wind speed. Second, the uncertainties in threshold determination for voids with different sizes and implant depths. As shown in Fig.16, the $\Delta \mathbf{C}$ (Eq.6) of the normalized contrast $\left(C_{n}\right)$ shows that it is not feasible to use a single threshold value to discriminate all voids during the entire period of hydration. It shows a range of values from 0.1 to 0.5 across size and implant depth at different time windows. However, due to the inclusive nature of the proposed extraction method (Eq.5), the value of 0.3 applied on $T_{n}$ is suggested for the visualization based on the authors' trial and error. Third, the experimental study reveals the potential correlations of detectability (temperature contrast) to the physical presence of the void (geometry and implant depth). This observation is agreed upon by several similar studies conducted for delamination detection [18,20,32,33]. However, the identified environmental factors along with the heating mechanism require further numerical studies.

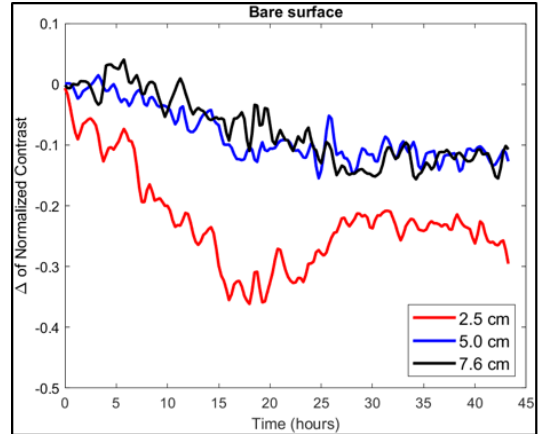

(a)

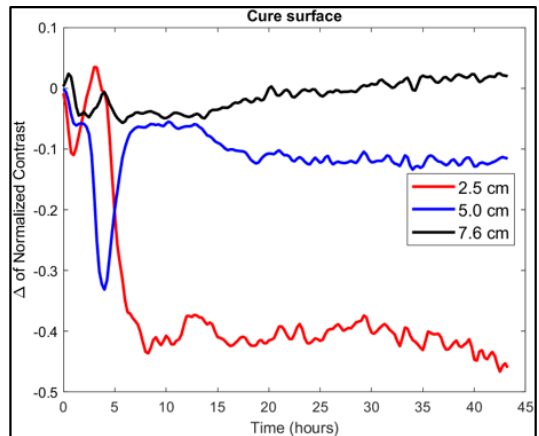

(b)

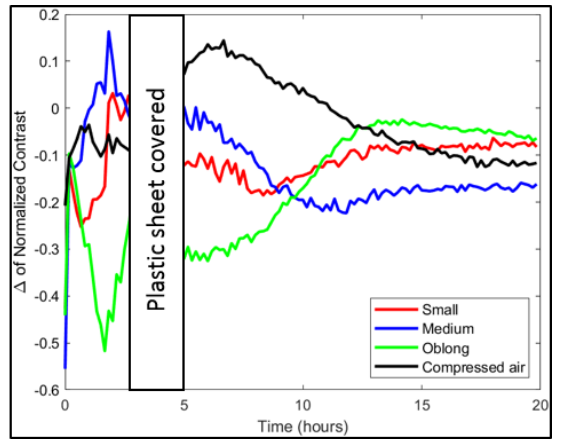

(c)

Figure 16. Results of $\Delta C$ : (a) bare surface of slab 1, (b) cure surface of slab 1, (c) slab 2.

\section{Conclusions}

This study introduces an approach to detect subsurface-void defects in fresh concrete during the stages of hydration. The absolute contrast and normalized contrast are proposed as measures to quantify the detectability. The outcomes of the quantitative investigation of the absolute contrast for voids in different sizes and implant depths show: 1) void defect presents negative values indicating the defect has a lower temperature than its surroundings during the hydration; 2) there is a trend that the contrast increases to a maximum and then decrease along with the hydration; 3 ) defects with the 
same size but in different depths return different maximum values: the shallower defect embedded, the larger value in the contrast; 4) defects with different sizes show a similar maximum contrast value but different time windows to reach: the larger size of the defect, the earlier time of the maximum contrast reached.

Through the analysis of the contrast of the normalized contrast image, it finds that the normalization decreases the contrast variations to some degrees along with the hydration which widens the time window to use a single constant threshold value for detection. In this study, the empirical value of 0.3 is suggested as the cut-off for defect extraction for the purpose of visualization enhancement.

Based on the investigation of several factors along with the contrast evaluation, the conditions that could affect the detectability are also discovered. The ambient temperature shows a reciprocal effect on the development of contrast: as the air temperature is rising, the contrast of void is decreasing. The optimal time window for detection is recommended between the later time of the hardening stage and early time of the cooling stage during the hydration, where the maximum contrast could occur. Finally, the non-uniformly placement of the curing compound would introduce additional noise to distort the visual appearance of the defect in the thermal image. However, the current study only proves the feasibility of detection with limited environmental variations. The field implementation requires more detailed investigations to account for factors of outdoor conditions.

\section{Acknowledgment}

The authors would like to thank the Nebraska Department of Transportation for their financial support through grant SPRP1(19) M082, and support in facilitating the data collection. The authors are also grateful for the collaboration of Dr. Erdogmus and Dr. Morcous and the assistance of UNL's lab manager Peter Hilsabeck in this project.

\section{References}

[1] F.E. Legg, Efficiency of vibrators in consolidating paving concrete, University of Michigan, Department of Civil Engineering, 1974.

[2] G.H. Tattersall, Workability and Quality Control of Concrete, 2014. doi:10.1201/9781482267006.

[3] J.R. Minnich, L.R. Mawhorr, N.E. Schipper, Accelerometer-based monitoring of concrete consolidation, (1999).

[4] J.K. Cable, L. McDaniel, R. Steffes, Evaluation of Paver Vibrator Frequency Monitoring and Concrete Consolidation, Iowa State University, 1999.

[5] Z. Tian, C. Bian, Visual monitoring method on fresh concrete vibration, KSCE J. Civ. Eng. 18 (2014) 398-408.

[6] Z. Tian, X. Sun, W. Su, D. Li, B. Yang, C. Bian, J. Wu, Development of real-time visual monitoring system for vibration effects on fresh concrete, Autom. Constr. (2019). doi:10.1016/j.autcon.2018.11.025.

[7] A.M. Alexander, R.W. Haskins, New field system for measuring degree of consolidation of concrete during vibration, Transp. Res. Rec. (1997). doi:10.3141/1574-16.

[8] P. Kosmatka SH, Voight GF, Taylor, Integrated Materials and Construction Practices for Concrete Pavement: A State-of-the-Practice Manual, 2006. doi:10.1017/CBO9781107415324.004.

[9] T. Omar, M.L. Nehdi, Remote sensing of concrete bridge decks using unmanned aerial vehicle infrared thermography, Autom. Constr. (2017). doi:10.1016/j.autcon.2017.06.024.

[10] A. Ellenberg, A. Kontsos, F. Moon, I. Bartoli, Bridge deck delamination identification from unmanned aerial vehicle infrared imagery, Autom. Constr. (2016). doi:10.1016/j.autcon.2016.08.024.

[11] C. Cheng, Z. Shang, Z. Shen, Bridge deck delamination segmentation based on aerial thermography through regularized grayscale morphological reconstruction and gradient statistics, Infrared Phys. Technol. (2019). doi:10.1016/j.infrared.2019.03.018.

[12] O. Büyüköztürk, Imaging of concrete structures, NDT E Int. (1998). doi:10.1016/S09638695(98)00012-7.

[13] S. Lin, D. Meng, H. Choi, S. Shams, H. Azari, Laboratory assessment of nine methods for 
nondestructive evaluation of concrete bridge decks with overlays, Constr. Build. Mater. (2018). doi:10.1016/j.conbuildmat.2018.08.127.

[14] I. Abdel-Qader, S. Yohali, O. Abudayyeh, S. Yehia, Segmentation of thermal images for nondestructive evaluation of bridge decks, NDT E Int. (2008). doi:10.1016/j.ndteint.2007.12.003.

[15] G. Washer, R. Fenwick, N. Bolleni, Effects of solar loading on infrared imaging of subsurface features in concrete, J. Bridg. Eng. (2010). doi:10.1061/(ASCE)BE.1943-5592.0000117.

[16] C. Cheng, R. Na, Z. Shen, Thermographic Laplacian-pyramid filtering to enhance delamination detection in concrete structure, Infrared Phys. Technol. (2019). doi:10.1016/j.infrared.2018.12.039.

[17] S. Hiasa, R. Birgul, F.N. Catbas, Investigation of effective utilization of infrared thermography (IRT) through advanced finite element modeling, Constr. Build. Mater. (2017). doi:10.1016/j.conbuildmat.2017.05.175.

[18] V.H. Mac, Q.H. Tran, J. Huh, N.S. Doan, C. Kang, D. Han, Detection of delamination with various width-to-depth ratios in concrete bridge deck using passive IRT: Limits and applicability, Materials (Basel). (2019). doi:10.3390/ma12233996.

[19] B.N.K. Raja, S. Miramini, C. Duffield, M. Sofi, P. Mendis, L. Zhang, The influence of ambient environmental conditions in detecting bridge concrete deck delamination using infrared thermography (IRT), Struct. Control Heal. Monit. (n.d.) e2506.

[20] T. Omar, M.L. Nehdi, T. Zayed, Infrared thermography model for automated detection of delamination in RC bridge decks, Constr. Build. Mater. (2018).

doi:10.1016/j.conbuildmat.2018.02.126.

[21] C. Cheng, R. Na, Z. Shen, Thermographic Laplacian-pyramid filtering to enhance delamination detection in concrete structure, Infrared Phys. Technol. 97 (2019). doi:10.1016/j.infrared.2018.12.039.

[22] C. Cheng, Z. Shen, The application of gray-scale level-set method in segmentation of concrete deck delamination using infrared images, Constr. Build. Mater. 240 (2020) 117974.

[23] H. Zhang, R. Yang, Y. He, A. Foudazi, L. Cheng, G. Tian, A review of microwave thermography nondestructive testing and evaluation, Sensors (Switzerland). (2017). doi:10.3390/s17051123.

[24] J.H. Jeong, D.G. Zollinger, Finite-element modeling and calibration of temperature prediction of hydrating portland cement concrete pavements, J. Mater. Civ. Eng. (2006). doi:10.1061/(ASCE)08991561(2006)18:3(317).

[25] C. Wang, W.H. Dilger, Prediction of temperature distribution in hardening concrete, RILEM Proc. 25, Therm. Crack. Concr. Early Ages. (1994) 21-28.

[26] M.J.M. Harrap, N.H. De Ibarra, H.M. Whitney, S.A. Rands, Reporting of thermography parameters in biology: A systematic review of thermal imaging literature, R. Soc. Open Sci. (2018). doi:10.1098/rsos.181281.

[27] A.A. Sultan, G. Washer, A pixel-by-pixel reliability analysis of infrared thermography (IRT) for the detection of subsurface delamination, NDT E Int. (2017). doi:10.1016/j.ndteint.2017.08.009.

[28] A.D. Restrepo-Girón, H. Loaiza-Correa, Background Thermal Compensation by Filtering for Contrast Enhancement in Active Thermography, J. Nondestruct. Eval. (2016). doi:10.1007/s10921016-0336-x.

[29] J.C. Forero-Ramírez, A.D. Restrepo-Girón, S.E. Nope-Rodríguez, Detection of Internal Defects in Carbon Fiber Reinforced Plastic Slabs Using Background Thermal Compensation by Filtering and Support Vector Machines, J. Nondestruct. Eval. (2019). doi:10.1007/s10921-019-0569-6.

[30] Morphological Image Analysis: Principles and Applications, Sens. Rev. (2000). doi:10.1108/sr.2000.08720cae.001.

[31] S. Doshvarpassand, C. Wu, X. Wang, An overview of corrosion defect characterization using active infrared thermography, Infrared Phys. Technol. (2019). doi:10.1016/j.infrared.2018.12.006.

[32] S. Hiasa, R. Birgul, F.N. Catbas, Effect of Defect Size on Subsurface Defect Detectability and Defect Depth Estimation for Concrete Structures by Infrared Thermography, J. Nondestruct. Eval. (2017). doi:10.1007/s10921-017-0435-3.

[33] C. Maierhofer, R. Arndt, M. Röllig, R. Helmerich, A. Walther, B. Hillemeier, C. Rieck, Quantification of Voids and Delaminations in Real Concrete and Masonry Structures with Active Thermography: Case Studies, in: 2006. doi:10.21611/qirt.2006.049. 